\title{
CORRESPONDENCE
}

\section{Sharing: project will make climate data freely available to all}

SIR - Some of the concerns expressed in your News story on the difficulties of collecting and sharing climate data across countries are unjustified (Nature 461, 159; 2009).

The World Meteorological Organization's task force is helping to develop a Global Framework for Climate Services to link weather predictions, projections and information with climate-risk management and adaptation. This international service will provide free and unrestricted collection and exchange of meteorological data.

Because the information is for the public good, there will be no competition or exclusion in accessing it. Application by one user will not reduce its availability to others. It would also be impossible - or very costly - to exclude potential users from using the data for their own benefit.

Another advantage is that although climate information is expensive to produce, it is relatively cheap to reproduce and distribute - making it economically efficient to supply these valuable data to all for free. Don Gunasekera Centre for Complex Systems Science, CSIRO Marine and Atmospheric Research, Commonwealth Scientific and Industrial Research Organisation, GPO Box 3023, Canberra, ACT 2601, Australia e-mail:don.gunasekera@csiro.au

\section{Sharing: public databases combat mistrust and secrecy}

SIR - You cite compelling reasons for the scientific community to share data (Nature 461, 145 and 168-173; 2009). But there is also a case for extending this to the broader community, including the general public.

Vertebrate palaeontology is a particularly rich candidate in this respect, as evidenced by blogging activity and busy internet traffic. Requests by amateur enthusiasts for copies of publications, measurements and photographs of fossils are commonplace.

To harness some of this enthusiasm, we launched the Open Dinosaur Project (http://opendino.wordpress. com) last month. Participants include students, professional scientists and artists, who enter measurements of fossil specimens from the literature and personal observation into a central public database. Participants may also contribute their expertise in data analysis and interpretation. All contributors will eventually be listed as authors on the first publication arising from the database.

Many older papers include data-rich tables of measurements, which are essential for comparisons between specimens. But there is a recent disturbing tendency to omit such information, even in studies that analyse hundreds of measurements for documenting evolutionary trends - perhaps because authors believe their exclusive access to the raw data gives them a competitive edge (Nature 461, 160-163; 2009). The Open Dinosaur Project data are owned jointly by the whole community, so this is no longer an issue.

Scientists lament the public's poor understanding and mistrust of science, and funding agencies want demonstration of 'broader impact' for research proposals. Public databases, particularly for engaging disciplines such as palaeontology and astronomy, may offer one solution.

Andrew A. Farke Raymond M. Alf Museum of Paleontology, Claremont, California 91711-2199, USA

e-mail: afarke@webb.org

Michael P. Taylor Department of Earth Sciences, University College London, Gower Street, London WC1E 6BT, UK Mathew J. Wedel Western University of Health Sciences, Pomona, California 91766-1854, USA

\section{Sharing: guidelines go one step forwards, two steps back}

SIR — The newly revised

Publication Manual of the American Psychological Association ranks among the most important books in the behavioural sciences and is one of Amazon.com's best-sellers in all book categories. Yet many research psychologists ignore its stipulations on the importance of data sharing.

The manual prescribes structure and style for scientific manuscripts, and deals with the ethics of publication. In this and earlier versions, authors are instructed not to withhold their raw data from other researchers who wish to verify the conclusions through reanalysis (citing standard 8.14 of the APA Ethics Code). It has been found, however, that $73 \%$ of psychologists publishing in high-impact APA journals failed to meet this obligation (J. M. Wicherts et al. American Psychologist 61, 726-728; 2006).

Unfortunately, the revised APA guidelines in the new edition aggravate the situation. They stress that data should be shared by written agreement: the agreement must specify conditions relating to the proposed use of the data (for example, for verifying results or for secondary analysis), limits on dissemination of re-analysis results, and authorship expectations. Although imposing such conditions on other researchers seeking to use the data for their own ends is reasonable, it will hinder datasharing for verification purposes.

Suppose that statistical flaws become apparent in a published paper. Under the new guidelines, these can't be investigated by an independent researcher unless the author agrees the terms for sharing the raw data. For instance, the author may demand to be a co-author on ensuing publications. It seems to us that the new APA guidelines will impede, rather than advance, the critical assessment of the quality of data analyses in psychology research.

Jelte Wicherts, Marjan Bakker Faculty of Social and Behavioural Sciences, Department of Psychology, Roetersstraat 15, 1018 WB Amsterdam, The Netherlands

e-mail:j.m.wicherts@uva.nl

\section{UK red tape as sticky as the US version for would-be students}

SIR - In a recent Editorial, you describe the arduous visa requirements applied to students or scientists seeking to enter the United States (Nature 461, 12; 2009). I experienced similar challenges and more as an American applying for a student visa to enter the United Kingdom.

My permanent residency in Europe counted for nought. Bewildering tangle of directives? Check. Mysterious acronyms? Check. Proof of money to cover expenses? Check. Uncertain waiting times? Check. The UK visa system has requirements not (yet) dreamed of in the United States, such as a letter from the admitting university not only confirming that the student has been accepted but also detailing why. The exam scores or reference letters used in the admittance decision also have to be included in the application process.

It is not only the United States that needs to consider balancing the need for security with allowing students and scientists reasonable terms of entry to the country.

Colin Stoneking Heinrichstraße 25, 04317 Leipzig, Germany e-mail: cjstoneking@gmail.com

Contributions to this page may be submitted to correspondence@ nature.com. Please see the Guide to Authors at http://go.nature. com/cMCHno. Comments and debate are also welcomed at our blog Nautilus (http://blogs. nature.com/nautilus). 